\title{
HISTORIA
}

\section{LA ENFERMERÍA Y EL CUIDADO DE LOS ENFERMOS MENTALES EN EL S. XV}

\author{
Amparo Nogales Espert
}

\author{
Av. Antic Regne de Valencia, 28 \\ 46005 - Valencia - España
}

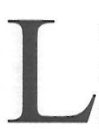

a ciudad de Valencia es especialmente significativa en cuanto a la asistencia a los enfermos por el buen número de hospitales con que cuenta desde la Baja Edad Media. Pero si tuviéramos que especificar sobre qué tipo de enfermos destacó la asistencia sanitaria en Valencia desde la antigüedad, sin duda hay que decir que es pionera en la asistencia a los enfermos dementes, puesto que desde principios del S. XV, contó con un hospital monográfico, el Hospital de Inocentes, exclusivamente dedicado a los enfermos mentales.

Este desarrollo de la asistencia sanitaria en la Valencia del cuatrocientos, se entiende si tenemos en cuenta que estamos ante una ciudad con una economía mercantil muy sólida, y con fuertes lazos comerciales con los más importantes puertos del Mediterráneo. Una ciudad en la que destaca una clase social de gran vitalidad, la burguesía comercial, que dará lugar al patriciado urbano, económicamente potente, creador e innovador.

Antes de estudiar el Hospital de Inocentes de Valencia, será interesante repasar el concepto de locura que se ha mantenido en distintas épocas de la historia (1).

\section{EL CONCEPTO DE LOCURA A TRAVÉS DE LA HISTORIA}

En la antigua Palestina el enfermo mental gozaba de una cierta consideración social, en ocasiones era valorado como un profeta.

La Grecia del siglo $\mathrm{V}$ considera al demente como un ser impuro, objeto de una maldición divina.

A lo largo de la época medieval y el Renacimiento se mantiene esta misma idea, y el enfermo mental se considera poseído por el poder maligno y portador de mal agüero. No es de extrañar la actitud desorientada u hostil de la sociedad ante el enfermo mental, especialmente virulenta cuando se trataba de enfermos provenientes de otra comunidad. En Alemania, los enfermos de otros lugares eran expulsados y devueltos a su ciudad natal.

Las ciudades despedían a los locos foráneos, que llevaban una existencia errante, recorriendo los campos y caminando de ciudad en ciudad.

Igualmente la locura se confunde durante tiempo con otros conceptos como el de brujería. De este modo los enfermos mentales se consideran peligrosos en sí mismos y merecedores de ser apartados de la sociedad.

\section{HOSPITALES, O CASAS DE LOCOS}

En el S. IV después de Cristo, aparece en Bizancio la primera casa de locos, llamada morotrophium, que funcionó para acoger a los enfermos afectos de locura.

Otra casa semejante existió en Jerusalén en el año 491 después de Cristo. Aunque pocos datos más se tienen respecto a estos primeros centros.

Durante los siglos IV y V, la regla de San Jerónimo ordenaba a los monjes la recogida de los enfermos mentales y su aislamiento; los enfermos recibían un tratamiento mínimo, e incluso se habla de que algunos enfermos sanaban.

Otras casas de locos aparecen descritas en diversos puntos de Europa, aunque no se sabe con seguridad si se trataba exclusivamente de Centros para este tipo de enfermos, o si eran Hospitales que dedicaban unas habitaciones para estos enfermos. 
Tampoco se sabe si se trataba de simples lugares de aislamiento con el único objetivo de apartar de la sociedad a estos afectados, o si contrariamente, los locos recibían especial asistencia.

Los enfermos locos en el año $560 \mathrm{~d}$. de C. eran atendidos en un monasterio en la ciudad de Colonia.

De igual modo, los enfermos mentales eran acogidos en varios monasterios en el año 850 , en la ciudad de Metz.

La ciudad de Gheel en Bélgica, en el año 1200 contaba en las proximidades de la iglesia, con una casa pobremente dotada, donde se atendía a los locos que permanecían a cargo de dos mujeres de avanzada edad, allí se recurría a encadenar a los más violentos como único recurso.

Posteriormente, en el S. XIV, existió un hospital próximo a la Torre de Londres, en esta ciudad; un hospital que atendía, además de a sacerdotes pobres, a otros enfermos, hombres y mujeres afectos de "frenesí".

Igualmente la ciudad de Roma contó, a finales del siglo XIV, con una Passarella, o lugar de locos.

Con respecto a la existencia de manicomios peninsulares de fundación posterior a la del Hospital de Inocentes de Valencia, se sabe de fundaciones en Zaragoza, Toledo, Palma de Mallorca, Valladolid y Barcelona, cuya fecha fundacional este último, data de 1412 .

La novedad del Hospital de Inocentes valenciano, erigido en 1409, es su dedicación exclusiva a la atención de los enfermos locos.

El mundo musulmán se distingue especialmente por su dedicación a la psiquiatría en sus hospitales medievales. Existen distintos criterios sobre el origen de los hospitales para enfermos dementes. Para unos el verdadero origen de esta especialidad asistencial es Bizancio, desde donde como meros difusores, los árabes la extendieron ampliamente. Otro sector de la investigación histórica asegura que el verdadero origen de los hospitales de locos, es árabe y procede de la ciudad de Bagdad.

Lo que podemos decir es que, en Al-Andalus, el primer hospital conocido fue el Maristan de Granada, construido por el sultán Mohamed V de 1365 1367, que se dedicó a enfermos mentales (2).

En cualquier caso es evidente la influencia que los países mediterráneos ejercieron en la fundación del Hospital de Inocentes valenciano, así como también fue decisivo el papel desempeñado por la Orden de la Merced, en este mismo sentido.

El especial interés de la cultura árabe por el mundo de la demencia se refleja en su libro sagrado, El Corán, en donde parece desprenderse la existencia de una consideración afectuosa hacia el enfermo demente, recomendándose que este tipo de enfermos debe ser encerrado y buscarse su curación.

En cuanto a la Terapia, algunos autores árabes nombran ciertos remedios para enfermos afectos de melancolía, frenesí o epilepsia:

Maimónides recomendaba el empleo de la música y de agradables conversaciones para los enfermos melancólicos.

Rhazes (850-923) la sangría para tratar el frenesí, la apoplejía y la migraña.

Abul-Casim (S.X) ordenaba practicar la cauterización en casos de apoplejía y de epilepsia.

\section{ORÍGENES DEL HOSPITAL DE INOCENTES}

Fray Juan Gilabert Jofré, religioso de la Orden de la Merced, y valenciano de nacimiento, es la principal figura en la fundación de esta institución hospitalaria. El año 1409, fecha precisamente en que se funda el hospital, era Comendador de la Orden en Valencia. Su papel protagonista ha sido frecuentemente descrito en la bibliografía "EI primer Domingo de Cuaresma, fray Juan Gilabert se dirigía a predicar el sermón en la Catedral, y durante el trayecto contempló el hecho desagradable de que varios locos habían sido acorralados y estaban siendo apedreados por un grupo de personas. Lleno de indignación protegió a los indefensos enfermos y preso de ese mismo estado de ánimo subió al púlpito y pidió al pueblo valenciano, apelando a su generosidad, que fundasen un hospital para acoger a los enfermos dementes. Tan directamente supo llegar a sus oyentes que se levantaron diez personas y ofrecieron cada uno veinticinco escudos, que hicieron un total de doscientos cincuenta ducados, lo que significó tan abundante limosna, que permitió comprar una casa y fundar una renta para su mantenimiento como hospital de locos" (3). 
¿Cómo pudo concebir Fray Juan Gilabert Jofré semejante idea de crear un hospital para dementes? Hay que tener en cuenta que la Orden de la Mercé a la que pertenecía, dedicaba sus principales actividades a la predicación de los infieles y a la redención de los cristianos que habían sido capturados como esclavos y se hallaban en manos de los musulmanes.

Por otra parte, y según sus datos biográficos, Fray Juan Gilabert había hecho varios viajes, entre 1392 y 1396 a Bugía, justamente para redimir cautivos. Y hacia 1400 se encontraba en Granada con la misma misión. Por tanto había tenido ocasión de conocer la cultura musulmana y su especial inclinación hacia el cuidado de los enfermos mentales y en definitiva, tenía más conocimientos al respecto, que la población valenciana.

Lorenzo Salom figura a la cabeza de los diez ciudadanos que voluntariamente se prestan para emprender la gran obra de creación de este hospital. La mayor parte de estos ciudadanos eran mercaderes y pertenecían al gremio de fabricantes de Tejidos de Seda y según las ordenanzas elaboradas para el seguimiento de la institución, los diez regidores debían ser ciudadanos, y claramente quedan excluidos los presbíteros, caballeros, dignificados, juristas o notarios, escogiéndose, como vemos, personas laicas y hombres llanos. Lorenzo Salom, además de protagonista entre los fundadores, fue el primer hospitalero que tuvo el Hospital de Inocentes.

\section{FUNDACIÓN DEL HOSPITAL DE INOCENTES}

¿Fue el Hospital de Inocentes de Valencia el primer manicomio del mundo? Para los historiadores de la Medicina española, este hospital valenciano fue el primer centro erigido y dedicado exclusivamente a la asistencia de los enfermos mentales, si exceptuamos el hospital d'en Colom, que desde 1375 había albergado a sacerdotes dementes, dirigido por tanto, a enfermos mentales de un sector social muy concreto.

Durante el siglo XV fueron apareciendo en diversas ciudades peninsulares, otras instituciones fundadas también con la intención de acoger a los enfermos mentales. En 1436 se creó en Sevilla un manicomio, fundado por el caballero Marcos
Sánchez Contreras, que desde el comienzo sufrió penurias económicas, quizá porque la ciudad de Sevilla tenía una autonomía política menor de la que gozaba Valencia y contaba con una burguesía menos extensa y pujante que la ciudad levantina. Desde su fundación se especializó en la recogida y asistencia de "los dementados y furiosos que vagaban por esa ciudad y arzobispado, no solo con peligro y riesgo de las personas cuerdas, sino con conocido daño de sí mismos, maltratándose con furor" (4)

Más tarde, en 1483, fue creado en la Ciudad de Toledo otro hospital de Inocentes y locos. Su fundador fue un religioso, don Francisco Ortíz, Nuncio y Canónigo de la Catedral; quién donó varias casas de su propiedad para este fin, poniendo la nueva institución bajo el gobierno del Cabildo de la Catedral. De este modo, el nuevo hospital pasó a depender de la Iglesia.

Años después en otra importante ciudad de Castilla, Valladolid, surgió un nuevo fundador, Sancho Vázquez, de la Cancillería quién, en 1489 dejó, en su testamento una parte de los bienes para que "sea erigido un hospital para recibir personas que por su enfermedad no estén en sus cabales". Este hospital igualmente estuvo administrado por la Iglesia, también a través del Cabildo Catedralicio.

Durante el siglo XV continuaron fundándose buen número de hospitales urbanos: Córdoba llegó a contar con treinta hospitales. Burgos con veintiocho, Salamanca con treinta, Astorga con veinte, León con diecisiete, Valencia con diecisiete, sin contar los de otras ciudades. Todos ellos eran hospitales de pequeño tamaño, dedicados desde su creación a la atención de diferentes personas y tipos de enfermedades.

A lo largo del tiempo, el reducido tamaño de estas instituciones puso de manifiesto su inoperancia debido al escaso número de enfermos que podían atender. Por lo que comenzó en los reinos hispánicos, un proceso de concentración hospitalaria, que significó también, la progresiva secularización de los hospitales de dependencia religiosa.

Al llegar la Edad Moderna, España se hallaba en la situación más avanzada de Europa en cuanto a la asistencia de enfermos mentales, pues contaba ya con tres hospitales exclusivamente dedicados al 
cuidado de locos e inocentes: Sevilla, Toledo y Valladolid, y siete hospitales generales que contaban con sendos departamentos para dementes: Barcelona, Valencia, Zaragoza, Lérida, Granada, Córdoba y Palma de Mallorca.

\section{DEPENDENCIAS DEL HOSPITAL DE INO- CENTES DE VALENCIA}

Respecto a la composición de sus departamentos, seguimos a Rodrigo Pertegas:

"...y que en su recinto se encontraba, además de la Iglesia y de los dos pabellones para alienados pobres, clasificados según el sexo, la casa de Mossen Johan Rodella, que seguramente es la que en los años posteriores se titula "casa del vicario"... la casa del majoral, donde tal vez se encontraban las habitaciones de los empleados; un molino y varios pabellones aislados para los dementes de posición social desahogada... (5).

Los dos pabellones para enfermos pobres, estaban compuestos al menos, por dos estancias, una de ellas era el comedor con ventanas para su ventilación protegidas con rejas de madera, que se comunicaba con grandes patios cubiertos de baldosas y rodeados de pórticos, para el paseo y distracción de los enfermos en días de lluvia.

El patio contaba con dos puertas de acceso al exterior; una, resguardada por una cancela, por la que se accedía al edificio, y otra de servicio, por donde se llevaban las heces de los recluidos, que evacuaban sus necesidades en vasos de obra (no existían retretes en esa época) y la basura del hospital, a vaciar en las letrinas.

\section{ASISTENCIA A LOS ENFERMOS}

De los médicos que asistían al Hospital de Inocentes, solo se conservan algunos nombres: Antoni Negre, Guillem Pedrera, Bartolomé Martí y también Jaume Roig, famoso escritor y médico de cámara del rey de Aragón Alfonso V el Magnánimo; fue médico del Hospital de Inocentes de 1469 a 1472. Además desempeñó el cargo de Mayordomo del Hospital, por lo que debió ser un buen conocedor de la institución.

El hospital seguía un estricto régimen disciplinario, impuesto por el hospitalero, del que más tarde hablaremos. Todos los reclusos que se hallaban en condiciones físicas adecuadas, estaban obli- gados a trabajar, pues se creía que la ociosidad permanente podía ser perturbadora para los dementes, y origen de malos hábitos y vicios. Por ello, una norma de la institución era tratar de evitar la inactividad. Los hombres trabajaban obligatoriamente en el jardín, en la granja, en la limpieza de los servicios y en el transporte y acarreo de material de abastecimiento, así como en las obras de albañilería. Las mujeres cosiendo y confeccionando vestidos y ropas de cama, hilando lino y cáñamo que luego era tejido, y realizando ciertas actividades de limpieza, como el lavado de la ropa personal.

Estas actividades de los enfermos perduraron en el tiempo, y en el siglo XVII, cuando las dependencias de los locos eran un departamento más del Hospital General de Valencia, algunos locos colaboraban en ciertas actividades de ayuda a otros enfermos del Hospital, por ejemplo, llevaban la bota de vino a los enfermos a quienes lo había prescrito el médico (6).

Así mismo, los internos más disciplinados y en mejor estado, realizaban actividades fuera del hospital, saliendo en grupos, bajo la vigilancia de un guardián, a pedir limosna apara ayudar a la institución, y también para recoger locos callejeros, o para atrapar algún fugado.

A los furiosos se les colocaban grilletes, o se introducían en jaulas o "gavies", inventadas por Jaume Roig, para su aislamiento en situaciones de crisis de violencia, a fin de hacer posible su contención y facilitar actividades de higiene.

La alimentación en la casa era sana, abundante y variada, y respecto al cuidado de los enfermos, se ponía especial esmero en la limpieza corporal de los pacientes mediante el baño, apartando a los que en las crisis estaban furiosos y sucios y encerrándoles en las jaulas antedichas.

Los dementes vestían uniformes hechos con sayos de tela gruesa, y una caperucilla de loco. Esta indumentaria era sustituida por otra de colores vistosos en los días de fiesta y cuando salían a pedir limosna repartidos por las iglesias de la ciudad. Y así, para ser reconocidos por seguridad de todos, y para evitar provocaciones, vestían "por divisa una cota a quadros u quartos encontrados y opuestos de amarillo y azul, y un casquete, o solideo, también de quatro cuadros de los mismos colores" (7). 


\section{MANTENIMIENTO ECONÓMICO DEL HOSPITAL}

En cuanto al mantenimiento del hospital, se lograba a través de varias fuentes de ingresos:

- Los diez miembros de la Junta Rectora del Hospital, debían abonar cada uno de ellos veinticinco libras cuando se hacían cargo del puesto.

- Las colectas realizadas por delegados especiales que provistos de privilegio real, o autorización civil o eclesiástica, recorrían ciudades y villas en festividades y días señalados.

- Posesión de Bulas papales. Concretamente Calixto III dio en Roma el $1^{\circ}$ de Septiembre de 1455 , una Bula que confirmaba la concedida por Benedicto XIII, por la que concedió indulgencias a todos los fieles cristianos que visitaran la iglesia del Hospital y contribuyeran con su limosna a las obras y mantenimiento de éste.

- Las limosnas pedidas por los propios dementes en la ciudad.

- Las donaciones y testamentos de particulares a favor del Hospital.

- El privilegio real que convirtió al Hospital en heredero de bienes muebles y ropas propiedad de los enfermos que fallecieran en la casa.

\section{PERSONAL ASISTENCIAL}

El personal estaba desempeñado por los siguientes funcionarios: Administrador $\mathrm{o}$ Mayordomo, Procurador, Escriva, Hospitaler y Dependientes.

Administrador o Mayordomo. Ostentaba el cargo de mayor responsabilidad y categoría. Tenía a su cargo el gobierno y dirección de la casa y de la administración de sus rentas. Se encargaba así mismo del nombramiento de los trabajadores de la casa, debiendo cuidar, como es natural, del buen funcionamiento de la institución. Este cargo debía estar obligatoriamente desempeñado por uno de los diez miembros que componían la Junta de Diputados del Hospital.

Procurador. Puesto que debía ocupar necesariamente un notario, ya que se encargaba de los aspectos económicos del Hospital, como recaudación de impuestos procedentes de legados, donativos, testamentos, limosnas y colectas.

También era representante y defensor de los intereses de la institución ante las autoridades civi- les y eclesiásticas.

Escrivá. Funcionario administrativo que actuaba como secretario en las juntas del Hospital, redactando las actas y dejando constancia escrita de los acuerdos adoptados en las sesiones celebradas en la casa.

Hospitaler. Figura fundamental en el hospital, encargado de realizar las funciones que actualmente corresponden a los Jefes o Directores de Enfermería. Su trabajo era muy importante y complejo. Para algunos autores (1) este puesto era el primero de los cargos subalternos. Para otros, "...La autoridad no estaba en manos de los médicos que supuestamente curaban a los enfermos, sino que era ejercida por el hospitaler..." (4).

Al hospitalero se le exigía dos condiciones: estar casado y residir en el hospital (8). Estas dos condiciones aluden a dos aspectos importantes para la enfermería: uno, que el personal con funciones de enfermería era personal laico, y además, que se trataba tanto de hombres como de mujeres. Por tanto la creencia de que en la antigüedad las enfermeras eran sobre todo mujeres y fundamentalmente adscritas a una orden religiosa, queda descartada. El otro aspecto se refiere a la obligatoriedad de residir en el Hospital, que podemos interpretar como reconocimiento de lo imprescindible del cuidado permanente de los enfermos hospitalizados, por parte del personal de Enfermería, identificado con este tipo de asistencia ininterrumpida.

Eran funciones del hospitalero las siguientes:

Recibir a los enfermos e indigentes. Atender directamente las necesidades de los enfermos. Así mismo vigilaba la limpieza y buen orden de las dependencias de la institución. Se encargaba de la preparación y distribución de la alimentación a los enfermos. Igualmente debía hacer cumplir al personal a su cargo, las ordenes y disposiciones del administrador.

Su mujer u hospitalera realizaba funciones de ayudante en los mismos aspectos, e igualmente se encargaba del mismo trabajo de asistencia a las mujeres hospitalizadas.

Para realizar las funciones asistenciales el Hospitaler y su mujer eran ayudados por los dependientes o empleados dedicados al cuidado permanente, es decir, encargados de las necesidades bási- 
cas de los dementes. Estos dependientes, igualmente llamados serviciales, aparecen en los hospitales medievales valencianos, también como encargados de las necesidades básicas de los enfermos: higiene, alimentación eliminación, movilización y de su cuidado permanente, es decir, realizando funciones de enfermería (8).

\section{CUIDADOS TERAPÉUTICOS}

Sobre la cuestión del tratamiento terapéutico dado a los dementes en el Hospital de Inocentes, unos autores piensan que no se trataba de una terapia psiquiátrica propiamente dicha, como dijo Rodrigo Pertegas para quien:

"Se consideraba a los locos como enfermos irremisiblemente desahuciados, cuya curación era imposible; y como se desprende de las palabras que se atribuyen al padre Jofré en el memorable sermón que fue origen de la fundación de este hospital, no se aspiraba a más que a subvenir a las necesidades corporales de los dementes y protegerlos contra la inclemencia del tiempo y contra las injurias de los hombres; a limpiar además con más o menos esmero, a los sucios; cohibir a la fuerza a los furiosos, y atender a todos, según las doctrinas médicas de la época, en las enfermedades intercurrentes y en los accidentes que pudieran sobrevenirles... no concebían los hombres del siglo XV que el loco fuera susceptible de curación" (9).

Diferente planteamiento es el de los que piensan que la psiquiatría empezó en el Hospital de Inocentes en el siglo XV. Algunos trabajos refieren como prácticas médicas el trato amable y paternal hacia los enfermos, el cuidado de la salud global, atendiendo plenamente a las necesidades básicas de los enfermos y la administración de una terapia ocupacional distribuida adecuadamente entre los enfermos leves.

Respecto al cuidado de la salud general, los enfermos dementes estaban bien atendidos en el Hospital, y bien alimentados. Recibían cuidados higiénicos, y en la primera mitad del siglo, cuando en el Hospital de Inocentes aún no se había construido departamento de baños, además de las reglas higiénicas habituales, los enfermos dementes eran llevados a una de las casas de baños de la ciudad, próxima al hospital, para practicarles el baño como medio higiénico y terapéutico.

Los dementes recibían los tratamientos propios de la medicina de la época, las técnicas de sangría, lavativas y las medicaciones conocidas para las diferentes enfermedades tales como purgantes, jarabes, elixires, tónicos.

Los médicos que atendían a los enfermos en el Hospital para enfermos dementes desde su fundación en la Valencia de principios del siglo $\mathrm{XV}$, se contaban entre los más importantes de la ciudad por ello puede decirse que estos enfermos, por lo que respecta a medicina general estaban bien asistidos, y bien atendidos por lo que se refiere a cuidados de enfermería.

En definitiva, desde mediados del siglo XV comenzará a producirse una verdadera medicalización en los centros asistenciales hospitalarios, de acuerdo con los nuevos valores que apuntaban ya en la sociedad que había comenzado un nuevo camino hacia la modernidad. (10).

El Hospital General de Valencia gozó de un gran prestigio, especialmente por su dedicación y experiencia en la asistencia de los enfermos mentales. Lope de Vega hizo del Hospital el escenario de una de sus comedias "Los locos de Valencia", escrita entre 1589 y 1604 , y por boca de uno de sus personajes dice del Hospital General:

"Tiene Valencia un Hospital famoso a donde los frenéticos se curan con gran cuidado y celo cuidadoso" (11).

La asistencia a los enfermos mentales se desarrollaría aproximadamente siguiendo la línea anteriormente descrita. El Hospital Real y General de Nuestra Señora de Gracia de Zaragoza, dedicado a la atención de estos enfermos desde que fuera fundado en 1425 por Alfonso V el Magnánimo, empleaba como medidas terapéuticas tres siglos después, los mismos tratamientos practicados por el Hospital de Inocentes de Valencia en el siglo $\mathrm{XV}$, destacando como el mejor de ellos, la Terapia Ocupacional, como consta en un texto de 1791:

"En cuanto al tratamiento, se emplean los baños de agua dulce, los refrescantes; pero estos medios son por lo general, infructuosos. Es así mismo difícil practicarles remedios durante sus accesos, sobre todo las sangrías pues pueden 
deshacer el vendaje; mas una experiencia constante ha demostrado en este Hospital que el medio más eficaz es la ocupación, 0 un trabajo que ejercite sus miembros. La mayor parte de los locos que se emplean en los talleres u oficios de la casa curan en general. La experiencia demuestra que los locos distinguidos que no se emplean nunca como los otros en ocupaciones serviles, o en los trabajos manuales, curan muy raramente" (12).

Hemos hablado del pasado. ¿Qué podemos decir sobre la salud mental del futuro? Gro Harlem Brundtland, Directora General de la Organización Mundial de la Salud, decía recientemente en un artículo: "Las enfermedades mentales adquieren (hoy), una mucho mayor dimensión. Pueden no ser mortales de por sí, pero provocan discapacidades prolongadas tanto en los países ricos como en los pobres, y van en aumento" (13) Por tanto los enfermeros especialistas en Salud Mental tienen interesantes perspectivas para desarrollar ampliamente su futuro profesional.

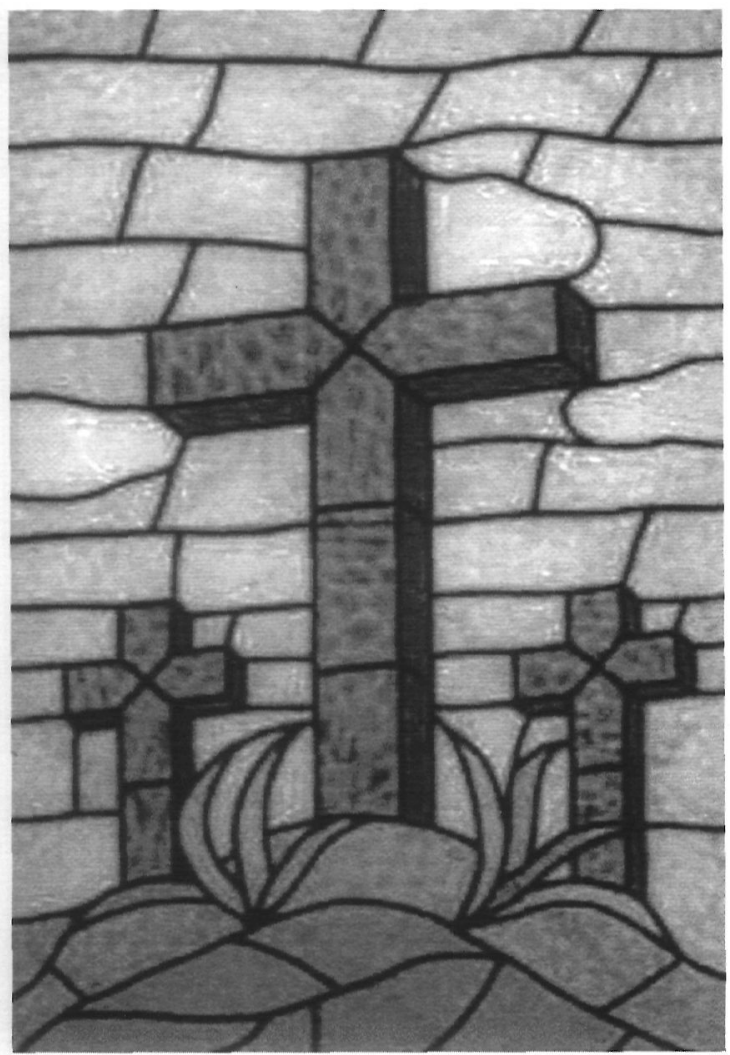

\section{BIBLIOGRAFÍA}

1.- SIMBOR ROIG, Ma J.1992 L'Hospital D'Inocents, folls e orats de València: Fonts de Bibliografía.

Tesis de Licenciatura. Facultad de Geografía e Historia. Universidad de Valencia

2.- NOGALES ESPERT, A.1996

El Islam y el Judaísmo.

En: Hernandez Martín, F. "Historia de la Enfermería en España. Desde sus orígenes hasta nuestros días". Editorial Síntesis. Madrid.

3.- CALATAYUD BAYÁ, J.1946

Juan Gilabert Jofré. Imprenta M. Guillot. Valencia.

4.- GONZALEZ DURO, E.1994

Historia de la locura en España. Tomo I. Siglos XIII al XVII. Ed. Temas de Hoy. Madrid.

5.- RODRIGO PERTEGAS, J.1923

La urbe Valenciana en el S. XIV. III Congreso de Historia de la Corona de Aragón.

6.- VILAR DEVIS, M.1996

El Hospital General en la Valencia Foral Moderna (1600-1700). Editorial Ayuntamiento de Valencia. Colección Estudis, $n^{\circ} 8$. Valencia.

7.- SEMPERE CORBI, J.

Cómo nació, cómo era, cómo funcionaba el Hospital de Sancta María dels Inocents. Valencia, 1559

8.- NOGALES ESPERT, A.1995

La Enfermería Medieval en Valencia a través de los Hospitales. II Congreso Nacional de Historia de la Enfermería. Málaga.

9.- RODRIGO PERTEGAS, J.1927

Hospitales de Valencia en el S. XV. Su administración, régimen interior y condiciones higiénicas. Rev. Arch. Bibliot. y Museos. Madrid.

10.- GALLENT MARCO, M.1988

La enfermedad, el personal sanitario y la asistencia. En: López Piñero, J.M ${ }^{a}$ "Historia de Medicina Valenciana". Tomo I. Edit. Vicent García. Valencia.

11.- LOPE DE VEGA, F.1996

Los locos de Valencia. Aguilar. Madrid.

12.- FERNANDEZ DOCTOR,

\section{A. 1987}

El Hospital Real y General de Ntra. Sra. Gracia de Zaragoza en el S. XVIII. Editorial Instituto Fernando el Católico. Zaragoza.

13.-HARLEM BRUNDTLAND, G.2000

Directora General de la Organización Mundial de la Salud. La Salud mental en el siglo XXI. Boletín de la O.M.S. Recopilación de artículos n 3 . 